\title{
Calendar of Events
}

September 16-19, 2007

IPOS 9th World Congress of Psycho-Oncology and Psychosocial Academy International Psycho-oncology Society (IPOS) "Integrating the Psychosocial to Achieve Quality Cancer Care"

Location: Imperial College, South Kensington Campus London, United Kingdom

Contact: IPOS Headquarters

Phone: +1-434-293-5350

Fax: +1-434-977-1856

E-mail: info@ipos-society.org

Web site: www.ipos-society.org

November 14-18, 2007

Academy of Psychosomatic Medicine (APM) 54th Annual Scientific Meeting

Location: Amelia Island Plantation Amelia Island, Florida

Web site: www.apm.org

2008

February 28-March 2, 2008

American Psychosocial Oncology Society (APOS) 5th Annual Conference

Location: Irvine, California

Contact: http://www.apos-society.org/apos2008/index.asp
March 19-21, 2008

PallCare 2008

The 2nd International Conference on Palliative Care In Different Cultures

Israel Palliative Medicine Society

Location: Eilat, Israel

Contact: Secretariat, c/o Stier Group, Ltd.

12 Tversky St; , Tel Aviv, Israel 67210

Tel: $++972-3-5626090$, line 8

Fax: $++972-3-5615463$

E-mail: palliative@stier.co.il

Web site: www.stier.co.il/palliative

\section{June 9-13, 2008}

IPOS 10th World Congress of Psycho-Oncology and Psychosocial Academy IPOS

Location: Feria de Madrid Convention Center

Madrid, Spain

Contact: IPOS Headquarters

2365 Hunters Way

Charlottesville, VA 22911, USA

Phone: +1-434-293-5350

Fax: +1-434-977-1856

E-mail: info@ipos-society.org

Web site: www.ipos-society.org 